\title{
Behavioral genetics in Cattle- a review
}

\author{
S. Fallahi
}

Animal Science Department, Amino Techno Gene Private Virtual Lab, Postcode: 1495845983, Tehran, Iran. Email: sepide.fallahi@gmail.com ; Phone: +989036745850

Journal of Livestock Science (ISSN online 2277-6214) 10:102-108

Received on 13/8/2019; Accepted on 22/10/2019

doi. 10.33259/JLivestSci.2019.102-108

\begin{abstract}
Behavioral traits are the main controllable factors for domesticating cattle. The traits profoundly influence on the longevity of cattle and play a remarkable role in animal welfare assessment and animal ethics limitations determination. In the present study, the genetics of cattle behavior is discussed. Current breeding status of cattle behavioral traits is also reviewed, regarding the high individual variation of behavioral traits and almost high correlations between the traits and performance. Moreover, recent findings of characterizing quantitative trait loci (QTL) for behavioral traits of cattle is considered, as well as the most important problems in the breeding of cattle behavioral traits such as a large variety of methods which are used to evaluate the traits.
\end{abstract}

Keywords: Cattle behavioral traits: Behavioral genetics: Cattle performance: Cattle breeding: Animal welfare: Animal ethics 


\section{Introduction}

There are main factors of the behavioral traits, including obedience and controllability, which can provide possibility of cattle domestication. Behavioral traits deeply affect cattle longevity are effective for assessment of animal welfare and determination of animal ethics ambit. Aurochs (Bos primigenius) were the first domesticated cows which were utilized for carrying and producing food such as milk, meat and blood. Cattle (Bos taurus) have been domesticated since approximately 8000 years ago (Pitt et al., 2019). Cattle utilize senses to communicate. So, behaviors and communication of cattle depend on perceptions through seeing, hearing and smelling. The communication plays effective roles on solidarity and structure of cattle herd (Phillips, 2015).Cattle behaviors are communicable ways between animal and environment. They are able to respond their vital needs for species survival against different conditions of environment (Broom and Fraser, 2015). Animal behavioral reactions depend on animal senses and sensory behavior and environment. Cattles have senses (seeing, hearing, smelling, tasting and touch) as same as other mammals. The most important behavioral traits, particularly in domestication and breeding, are ability for gradual reducing fears of human, ability to subordinate gradually to human as a dominant living creature, ability to learning desirable behaviors and responses and ability for breeding and feeding by human. Breeders have considered behavioral traits as practical traits in breeding, since the influences of the traits on cattle longevity have been characterized (Pienaar et al., 2015). Flexibility of behavioral traits of cattle which adapts with human-made conditions are used in domestication process and genetic breeding (Adamczyk, 2018). The traits are the foundation of human-animal relationship and consequently performance; as well as behavioral disorders including lameness, biting, tongue rolling, excessive licking and Self-treatment by buller steer syndrome (Friedrich et al., 2015). Target Bos taurus strains selection is caused by behavioral characteristics and changes (Michenet $e$ al., 2016). Flexibility in behaviors enables animal to live in conditions created by human, as well as breeders to obviate requirements of cattle to achieve higher performance (Grandin, 2018). The behavioral traits are playing roles in breeding program, in many countries, although assessment of the traits is more difficult than productive traits. It could be caused by improvement of behaviors and genetics of cattle and effective environmental factors(Broom and Fraser, 2015). Therefore, the purpose of the study is review of the prominent issues in effective breeding of cattle behavioral traits, such as phenotypic evaluation and using molecular population genetics for estimation of genetic parameters and breeding values.

\section{Behavioral traits definition}

Cattle behavior is a brain-body function based on molecular pathways and genetic diversity. Behavioral flexibility and learning aptitude of cattle have been improved more than other mammals including rodents, cats and horses (Xu et al, 2018). The temperament, as a general animal trait, includes behaviors such as physical activity level, usual habits, feelings, consciousness and curiosity. According to several reports, animal temperament is caused by interaction of simulative-inhibitive reactions (Mishenevaet al, 2018).Phillips (2015) has defined temperament as a main animal character in relation with human. Milking temperament of cattle has been defined as cattle milking behaviors, ease of manipulation and aggression during feeding (Kruget al, 2017). According these definitions, different methods are employed to evaluate cattle temperament in breeding programs and studies. Several methods have been categorized to evaluate cattle temperament in unlimited and limited scoring test system, free motion test and evaluation of maternal temperament (Bruno et al., 2018).

\section{Fear as a basic criterion for cattle temperament assessment}

Temperament is the most important trait of animal for determination cattle perceptionand response to different conditions. This response could be a habitual behavior which has been possibly stable in different fields during cattle life. Observable appearances of cattle temperament are included reaction behaviors (Vogt et al., 2017). Reaction against human is widely influenced by previous experiences related to communication with human and environmental changes. Fear is strong and emotional status to plays prominent roles to avoid potential dangerous conditions. Response for facing danger could be evaluated by behavioral and mental measurements (Lindahl et al., 2016).Fear can be generally activated by environmental stimulators which are related to previous unpleasant experiences such as intense light, noise, sudden motions, touching and aggression. The most remarkable and observable reactions include active reaction (active defense and attacking), active avoidance (escaping and hiding) and inactive reaction (immobility, urine and feces) (figure 1). Active and inactive reactions can appear during challenging situations (Abramson and Kieson, 2016).There are considerable other types of behavioral patterns, such as standing position, facial expression, voices and releasing pheromones in fear appearance. Fear can be considered as the main mental factor. Although this is a temporary feeling, it can reflect the animal character. So, fear level has been considered as a main criterion for evaluating cattle temperament (Brand et al., 2015).

It seems that fear, as the main factor, can affect quality of human-animal relationship (HAR). There can be found many applicable tests, designed based on reactions of cattle, pig, sheep, poultry and horse, to evaluate fear responses for measurement of HAR quality (Patterson-Kane and Johnson, 2018). Fear responses are very complex and cannot be automatically measured; it is required to evaluate criteria and indices related to fear. On the other hand, environment can mostly influence on cattle reactions; so, precision measurement of fear responses might be difficult, sometimes impossible. Behavioral responses could be observed as criteria and indices of fear, but not 
measured directly. Diversity of environmental conditions in different studies is considered as another concern. Consequently, interpretation of results would be difficult (Menéndez-Buxaderaet al., 2017).

\section{Cattle temperament assessment for breeding purposes}

Assessment of cattle temperament, such as milking, is considered for breeding purposes. There are different numeric criteria for the purpose. In many countries, including Denmark, Sweden and Finland, the assessment is categorized and estimated by consulters via artificial fertility techniques, when a cattle is firstly fertilized after calving (Ebinghaus et al., 2016). High scores belong to calm cattle or nervous one. According to animal behaviors observation in new environment, temperament assessment is mostly mental in beef cattle, although objective methods are used such as avoiding distance(Monk et al.,2018).

\section{Objective measurements for cattle behavior assessment}

Assessment of individual behavioral characteristics by application of objective measurements is essential to use cattle behavioral information for breeding. Reported studies can indicate some probabilities; as an example, it has been reported that the thickness and width of cylindrical bone of cattle is significantly related to cattle temperament (Parham et al., 2019).Convoluting facial hair near eyes of male cattle is considerable for objective measurement of temperament (figure2) (Bruno et al., 2018).

The aforementioned traits could be employed as accurate criteria for cattle temperament assessment; even probably other behavioral traits (Bruno et al., 2018). In last decade, technological developments have provided tools to develop systems for real time assessment of cattle behavior. Nowadays, cattle behaviors can be studied by Global Positioning System (GPS), Geographic Information System (GIS) in outdoor (pastures) or by tracking and monitoring systems such as X-Y-Z- Positioning in 3D and 2D space in indoor (figure3). Above reported methods could be employed for assessment of cattle temperament and other behavioral traits in different ages and growing conditions (Mora-Delgado et al., 2016).

\section{Population genetics and behavioral traits of cattle \\ i) Diversity in behavioral traits}

Behavioral traits of cattle are characterized by high significant individual diversity. Moreover, cattle are naturally observed in herd; they do several activities and utilize similar behavioral patterns. The high diversity allows animals to show their behaviors (Lim et al., 2016). There is high diversity of cattle behaviors related to feeding, rumination (figure 4), obedience to enter the milking room (Walker et al., 2015).In another report, high individual diversity has been observed in physical activity per a day for Holstein - Friesian cattle in welfare conditions (Adamczyk et al., 2017). Also, high diversity of Nellore cattle temperament has been assessed by using four scoring criteria (Verdon et al., 2018).

\section{ii) Heritability of cattle behavioral traits andgenetic correlation with production traits}

Generally, cattle heritable behavioral traits have been accepted as quantitative traits which are influenced by gene additive effects. The traits increasingly depend on single gene effects; for instance, temperament has been more considered among all the behavioral traits of the cattle. It has been indicated that heritability coefficient of temperament, estimated by using assessment methods in similar productive systems, has been significantly different with heritability based on animal age and genotype (Stephansen et al., 2018). There is also high diversity of heritability of cattle temperament (Miglior et al., 2017). Cattle temperament heritability parameters have been estimated 0.18-0.22 and 0.25 for Holstein - Friesian and Jersey, respectively (Mirza et al., 2015).In addition, heritability index of cattle temperament has been reported 0-0.61 and 0.11-0.31 for beef cattle (Vogt et al., 2017).Almost high heritability index $(0.36,0.44$ and 0.5$)$ have been recorded for nutritional behaviors (duration, and speed of feeding respectively; figure 5) of hybrid cattle of Bos taurus and Bos indicus. There is low or medium heritability for social and reproductive behaviors. Studies have been demonstrated that cattle temperament is a behavioral trait that correlates with function of milk, milk production and milking (Llonch et al., 2018). According to another research, cattle longevity is reduced by anxiety. Temperament and nutritional behavior are mostly related to meat performance trait (Olechnowicz et al., 2016). Also, there is almost high genetic relation between obedience and fertility in Limousine heifers (Valente et al., 2017).

\section{iii) Cattle behavioral traits breeding}

Temperament is the most considerable behavioral trait of cattle for breeders. Calm cattle breeding have been significantly increased by long term removing nervous cattle from breeding process; but there is a concern about this removing in both beef and dairy cattle. To exemplify, the results of dairy cattle population assessment have indicated that temperament of more than 90 percent of cattle which are milked is moderately calm or very calm (Hedlund and Løvlie, 2015); as well as results were considerable when more anxious cattle were selected for milking. In a study, a significant increasing of the average breeding value was found for the trait from 1980 to 1999. Comparison of breeding value has been made difficult in different countries due to various methods for assessment of dairy cattle temperament (Pelayo et al., 2016). 


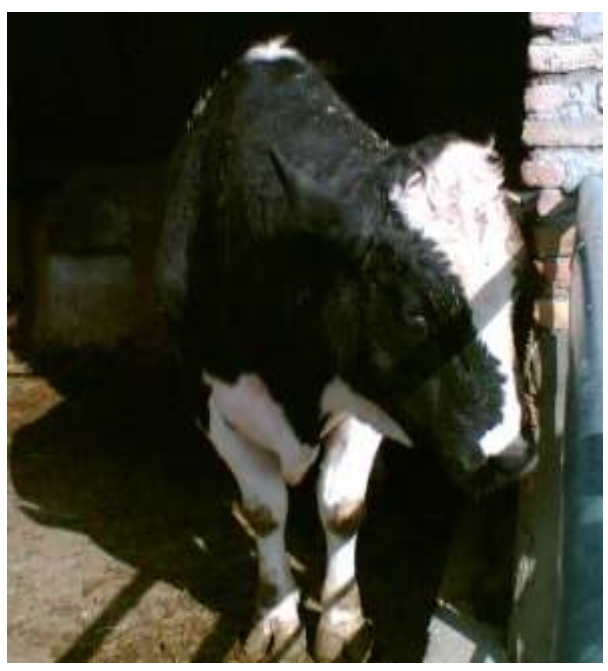

Fig 1 Active avoidance (being hidden)

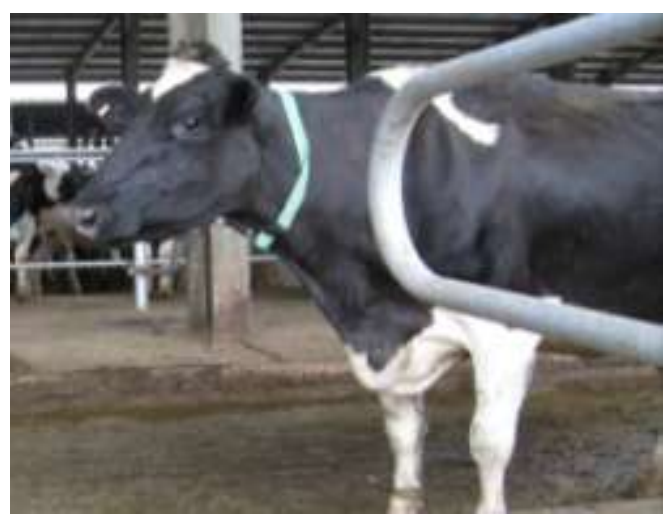

Fig 3 Tracker collar

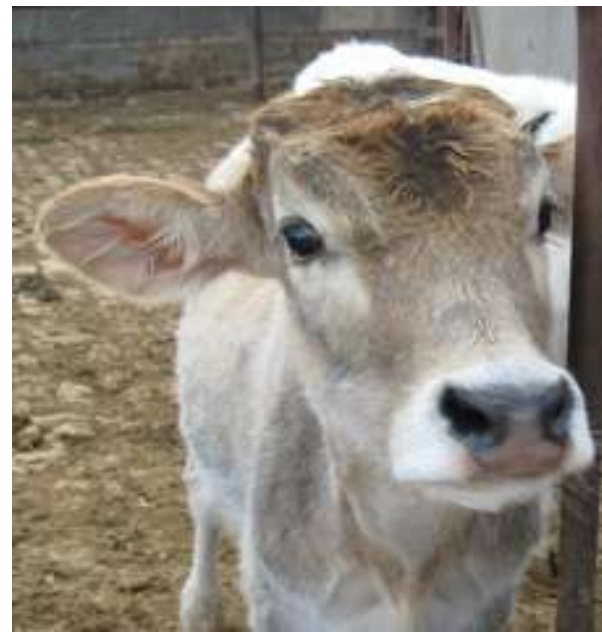

Fig 2 Convoluting facial hair could be considered for Cattle temperament assessment

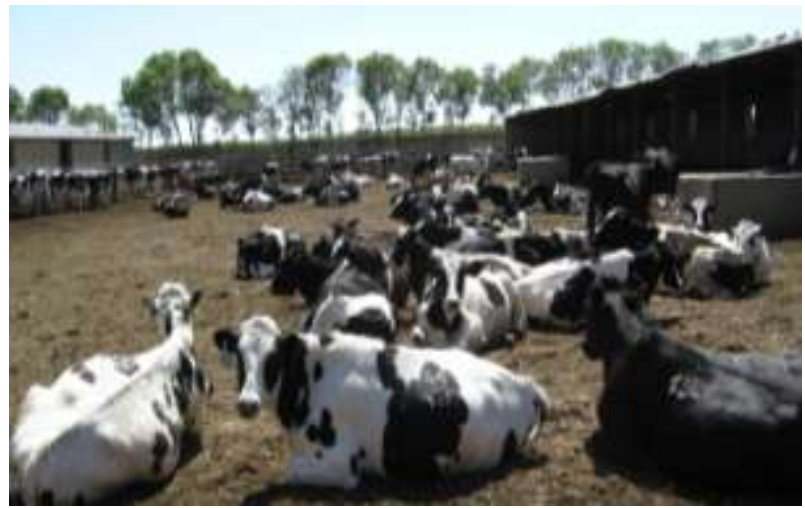

Fig 4 "Ruminating" as a behavioral trait

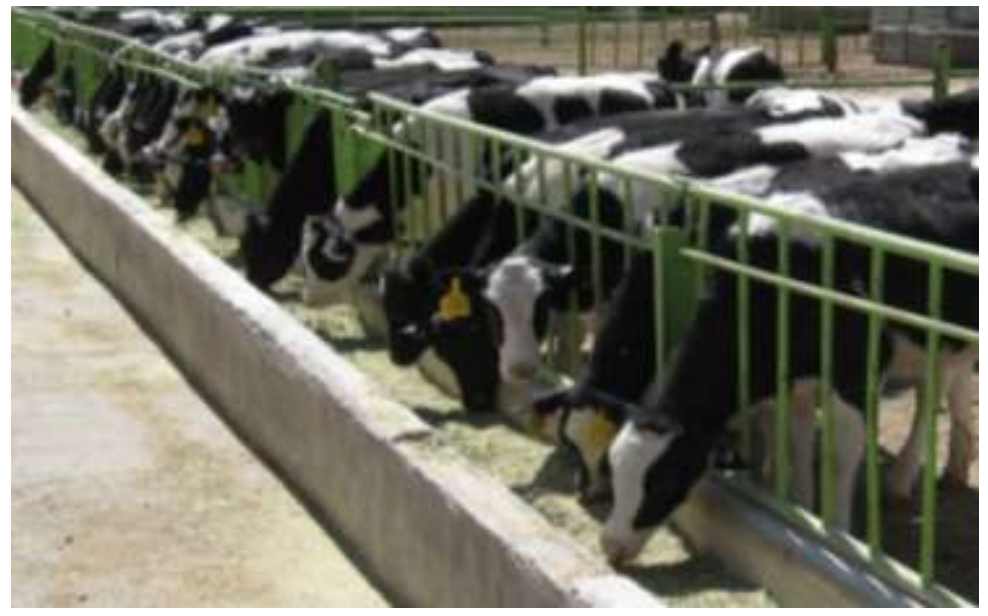

Fig 5 Nutritional behaviors (duration, and speed of feeding)

\section{Molecular genetics and cattle behavioral traits}

i) Quantitative trait loci effect on cattle behavioral traits

About 6305 quantitative trait loci (QTL) have been characterized, mapped and designed for 416 different cattle traits. Discovering for effects of QTL on behavioral traits has been less successful than QTL characterization. The effects have been studied in other animals particularly mouse and farm animals such as poultry and pig (Brand et al., 2016). Researchers specifically concentrate on temperament and ability for habit and acclimatization more 
than other behavioral traits. There are about 44 QTL on most of the chromosomes, except 2, 13, 17, 22, 23, 24 and 27, for temperament and ability for habit and acclimatization. The QTL can be mostly found on 1, 4, 9, 16, 19 and 29 (dos Santos et al., 2017). The significant distribution in cattle genome which determines animal behavior, may be mainly caused by using different research methods within a trait. Also, primary results of gene evaluation show that there is a requirement to use increasingly molecular genetic markers for improvement of applicability of studies to discover candidate genes for cattle behavioral traits (Laine and van Oers, 2017).

\section{ii) Candidate genes for cattle behavioral traits}

Genetic maps structure of several farm animals species and efforts to improve animal welfare in different key systems, have increased research on genetics of behavioral traits. Identifying molecular mechanisms of behaviors might be effective to understand common problems in many productive fields of animal such as manipulation, sensitivity and tolerance to stress or acclimation to different productive systems (Chen et al., 2015). It is supposed that characterizing QTL of cattle behavioral traits causes to characterize candidate genes which are near the genetic markers and highly effect on the specific trait; nevertheless, the method is not generally effective due to high complexity of animal individual behaviors expression and reactions to environment (Neave et al., 2018). Up to now, just a few published studies have reported the genes which might contribute to appearance of temperament, nutritional and reproductive behaviors of cattle. The reports have studied polymorphism of the genes which are active in biosynthesis of stress hormones, neural peptides and neurotransmitters (Van Engen and Coetzee, 2018). In a study, expression of gene which encodes heat shock protein is used to primarily diagnose symptoms of bovine respiratory disease complex. According to the results, it is demonstrated thatthe gene is expressed to response to stress (Lipkin et al., 2016). Polymorphism of the gene of the bovine neuropeptide Y5 receptor shows that the gene can potentially regulate Y5 activity and might play key role in regulation of beef cattle appetite and nutritional behavior (Adamczyk, 2018).Also, it is indicated that there can be found correlation between expression of GFRA2 (GDNF Family Receptor Alpha 2) gene and residual feed intake (Higgins et al., 2018). In another similar study, polymorphism of the gene, encoding melanocortin 4 receptor (MC4R), has been employed as a genetic marker of cattle commercial traits. It is indicated that the gene probably affects feed intake rate and nutritional behaviors (Prihandiniet al., 2017). Identification of genes which can affect cattle behavioral traits, showed that there is a correlation between gene expression in cattle ventral tangential region and appearance of stress in highproducing Holstein- Friesian cattle (Wiener, 2015).Genes of several neurotransmitters and neurotransmitter receptors (OXT, AVP, POMC and MCHR1) are expressed to collaborate in appearance of estrous behaviors such as social and sexual nervousness, stress and nutrition motivation (Imran et al., 2018).

Conclusion

Characterizing cattle behaviors is essential to enhance cattle performance based on animal welfare and rights. The effect of light, hormones and genetic factors on cattle behaviors would be studied more. Cattle behavioral traits could be increasingly considered in recent breeding program due to importance of the traits. It seems that there is hopeful prospect to develop behavioral traits with respect to molecular and population genetics; because these traits are significantly various and favorably correlative with other traits such as productivity. Nevertheless, it is required to provide obvious phenotypes of cattle individual traits and use objective methods as criteria of breeding values in productive systems for practical applications of behavioral genetics research.

\section{Acknowledgement}

The author is so grateful to Mr. Reza Mohammadhassan, the headmaster of Amino Techno Gene virtual Lab. (NGO), for supporting the study.

\section{References}

1) Abramson C I and Kieson E. 2016. Conditioning methods for animals in agriculture: A review. Ciência Animal Brasileira17(3): 359-375.

2) Adamczyk K. 2018. Dairy cattle welfare as a result of human-animal relationship -a review. Annals of Animal Science, 1(ahead-of-print) 18(3): 601-622.

3) Adamczyk K, Cywicka D, Herbut P and Trześniowska E. 2017. The application of cluster analysis methods in assessment of daily physical activity of dairy cows milked in the Voluntary Milking System. Computers and Electronics in Agriculture 141: 65-72.

4) Brand B, Hadlich F, Brandt B, Schauer N, Graunke K L, Langbein J,Repsilber D, PonsuksiliS and Schwerin M. 2015. Temperament type specific metabolite profiles of the prefrontal cortex and serum in cattle. PloS one 10(4): e0125044.

5) Brand B, Scheinhardt M O, Friedrich J, Zimmer D, Reinsch N, Ponsuksili S, Schwerin Mand Ziegler A. 2016. Adrenal cortex expression quantitative trait loci in a German Holstein $\times$ Charolais cross. BMC genetics 17(1): 135 . 
6) Broom D M and Fraser A F. 2015. Domestic Animal Behaviour and Welfare.5th Ed, pp. 472. Wallingford: CABI.

7) Bruno K, Vanzant E, Vanzant K, Altman A, Kudupoje M and McLeod K. 2918. Relationship between quantitative measures of temperament and other observed behaviors in growing cattle.Applied Animal Behaviour Science 199: 59-66.

8) Chen Y, Arsenault R, Napper S and Griebel P. 2015. Models and methods to investigate acute stress responses in cattle. Animals 5(4): 1268-1295.

9) dos Santos F C, Peixoto M G C D, de Souza Fonseca P A, Pires M D F Á, Ventura R V, Rosse I D C, Bruneli FA,Machado MA and Carvalho M R. 2017.Identification of candidate genes for reactivity in Guzerat (Bos indicus) cattle: a Genome-wide Association Study. Plos one 12(1): e0169163.

10) Ebinghaus A, Ivemeyer S, Rupp J and Knierim U. 2016.Identification and development of measures suitable as potential breeding traits regarding dairy cows' reactivity towards humans. Applied Animal Behaviour Science 185: 30-38.

11) Friedrich J, Brand B and Schwerin M.2015. Genetics of cattle temperament and its impact on livestock production and breeding- a review. Archives Animal Breeding 58(1): 13-21.

12) Grandin T. 2018.Livestock-handling assessments to improve the welfare of cattle, pigs and sheep. Animal Production Science 58(3): 403-407.

13) Hedlund L and Løvlie H. 2015.Personality and production:Nervous cows produce less milk. Journal of Dairy Science 98(9): 5819-5828.

14) Higgins M G, Fitzsimons C, McClure M C, McKenna C, Conroy S, Kenny D A, McGee M, Waters S M and Morris D W. 2018. GWAS and eQTL analysis identifies a SNP associated with both residual feed intake and GFRA2 expression in beef cattle. Scientific Reports 8(1): 14301.

15) Imran S, Maryam J, Nadeem A and Iqbal M. 2018.Pretentious genomic selection signatures in CYP19A1 gene associated with silent estrous behavior in water buffalo in Pakistan. Electronic Journal of Biotechnology 32: $35-40$.

16) Krug C, DeVries T J, Roy J P, Dubuc J and Dufour S. 2017.Incomplete milking in early lactation does not affect dairy cows resting behaviors: Results from a randomized controlled trial.Frontiers in Veterinary Science 4: 66.

17) Laine V N and van Oers K. 2017.The Quantitative and Molecular Genetics of Individual Differences in Animal Personality.Personality in Nonhuman Animals, Vonk J, Weiss A, Kuczaj S, Springer, Cham. 55-72.

18) Lipkin E, Strillacc M G, Eita H, Yishay M, Schiavini F, Soller M, Bagnato A and Shabtay A. 2016. The use of Kosher phenotyping for mapping QTL affecting susceptibility to bovine respiratory disease. PloS one 11(4): e0153423.

19) Lim D, Strucken E M, Choi B H, Chai H H, Cho Y M, JangG W, Kim T H, Gondro C and Lee S H. 2016.Genomic footprints in selected and unselected beef cattle breeds in Korea. PloS one 11(3), e0151324.

20) Lindahl C, Pinzke S, Herlin A and Keeling L J. 2016. Human-animal interactions and safety during dairy cattle handling-comparing moving cows to milking and hoof trimming. Journal of Dairy Science 99(3): 21312141.

21) Llonch P, Mainau E, Ipharraguerre I R, Bargo F, Tedó G, Blanch M and Manteca X. 2018. Chicken or the Egg: The Reciprocal Association Between Feeding Behavior and Animal Welfare and Their Impact on Productivity in Dairy Cows. Frontiers in Veterinary Science 5.

22) Menéndez-Buxadera A, Cortés O and Cañon J. 2017.Genetic (co) variance and plasticity of behavioral traits in Lidia bovine breed. Italian Journal of Animal Science 16(2): 208-216.

23) Michenet A, Saintilan R, Venot E and Phocas F. 2016. Insights into the genetic variation of maternal behavior and suckling performance of continental beef cows. Genetics Selection Evolution 48(1): 45

24) Miglior F, Fleming A, Malchiodi F, Brito L F, Martin P and Baes C F. 2017.A 100-Year Review: Identification and genetic selection of economically important traits in dairy cattle. Journal of Dairy Science 100(12): 10251-10271.

25) Misheneva V, McFarland R, Jouroukhin Y, Severance E, Yolken R and Pletnikov M. 2018. F101. Animal Models of Mood Disorders and the Evaluation of Probiotics. Biological Psychiatry 83(9): S276-S277.

26) Mirza R H, Javed K, Akhtar M, Rauf M, Khan M A, Ali M and Tipu S M R D. 2015. Environmental Factors Affecting Linear Classification of Top Line and Feet and Leg Traits in Nili Ravi Buffaloes of Pakistan. Journal of Agricultural Engineering and Biotechnology 3(3): 84-91.

27) Monk J E, Hine B C, Colditz I G and Lee C. 2018.A Novel Protocol to Assess Acclimation Rate in Bos taurus Heifers during Yard Weaning. Animals 8(4): 51.

28) Mora-Delgado J, Nelson N, Fauchille A and Utsumi S. 2016.Application of GPS and GIS to study foraging behavior of dairy cattle. Agronomía Costarricense 40(1): 81-88.

29) Neave H W, Weary D M and von Keyserlingk M A G. 2018. Individual variability in feeding behaviour of domesticated ruminants. Animal 12(s2): s419-s430.

30) Olechnowicz J, Kneblewski P, Jaśkowski J M and Włodarek J. 2016.Effect of selected factors on longevity in cattle: a review. Journal of Animal and Plant Sciences 26(6): 1533-1541 
31) Parham J T, Tanner A E, Barkle K, Pullen L, Wahlberg M L, Swecker Jr W S and Lewis R M. 2019.Temperamental cattle acclimate more substantially to repeated handling. Applied Animal Behaviour Science 212: 36-43

32) Patterson-Kane E and Johnson C. 2018.The human-animal bond: A Risk and Asset for Animal-Based Agriculture. The Business of Farm Animal Welfare, (Eds) Amos N and Sullivan R, $1^{\text {st }}$ edn, Routledge, 137-155.

33) Pelayo R, Solé M, Sánchez M J, Molina A and Valera M. 2016.Behavioural linear standardized scoring system of the Lidia cattle breed by testing in herd: estimation of genetic parameters. Journal of Animal Breeding and Genetics 133(5): 414-421.

34) Phillips C. 2015. Welfare and cattle behaviour.Bovine Medicine. (Ed) Cockcroft P D, pp 291.

35) Pienaar L, Neser F W C, Grobler J P, Scholtz M M and MacNeil M D. 2015. Pedigree analysis of the Afrikaner cattle breed. Animal Genetic Resources/Resources génétiques animales/Recursos genéticos animals57: 5156.

36) Pitt D, Sevane N, Nicolazzi E L, MacHugh D E, Park S D, Colli L, Martinez R, Bruford M W and OrozcoterWengel P. 2019. Domestication of cattle: Two or three events. Evolutionary Applications 12(1): 123136.

37) PrihandiniP W, Sumadi S, Budisatria I and Maharani D. 2017.Identification Single Nucleotide Polimorphism of Melanocortin 4 Receptor Gene in Madura Cattle.The 7th International Seminar on Tropical Animal Production, Faculty of Animal Science, Universitas Gadjah Mada, ISSTAP (pp. 691-695)

38) Stephansen R S, Fogh A and Norberg E. 2018. Genetic parameters for handling and milking temperament in Danish first-parity Holstein cows.Journal of Dairy Science 101(12): 11033-11039.

39) Valente T S, Albito O D, Sant'Anna A C, Carvalheiro R, Baldi F, Albuquerque L G and da Costa M P. 2017.Genetic parameter estimates for temperament, heifer rebreeding, and stayability in Nellore cattle. Livestock Science 206: 45-50.

40) Van Engen N K and Coetzee J F. 2018. Effects of transportation on cattle health and production: a review. Animal health research reviews 1-13

41) Verdon M, Rawnsley R, Raedts P and Freeman M. 2018.The behaviour and productivity of mid-lactation dairy cows provided daily pasture allowance over 2 or 7 intensively grazed strips. Animals 8(7): 115 .

42) Vogt A, Aditia E L, Schlechter I, Schütze S, Geburt K, Gauly M and von Borstel U K. 2017.Inter-and intraobserver reliability of different methods for recording temperament in beef and dairy calves. Applied Animal Behaviour Science195: 15-23.

43) Walker J K, Arney D R, Waran N K, Handel I G and Phillips C J. 2015.The effect of conspecific removal on behavioral and physiological responses of dairy cattle. Journal of Dairy Science 98(12): 8610-8622.

44) Wiener P. 2015. Genetics of behaviour in cattle. The Genetics of Cattle. (Eds) Garrick D J, Ruvinsky A. CABI.

45) Xu J, Wang H, Shen Y, Zhao R, Ge R, Yu L and Wang M. 2018. Impact of dietary carbohydrate balance on rumen fermentation, eating behaviour, growth and development of 8-10-month-old heifers. Animal Production Science 58(11): 2042-2048. 